\section{Earthquake Loss Evaluation (ELE) for the City of Khujand, Sughd Province, Tajikistan}

Gl_Forum 2016, Vol.2

Page: 74-89

Full Paper

Corresponding Author:

niyazovjafar@mail.ru

DOI: 10.1553/giscience2016_02_s74

Jafar Niyazov', Dominik H. Lang² and Abdelghani Meslem²

1 Academy of Sciences, Dushanbe, Republic of Tajikistan

2 NORSAR, Kjeller, Norway

\begin{abstract}
The main scope of the present article is to describe the different technical aspects and steps that were implemented towards a thorough earthquake risk estimation for the city of Khujand, the capital of Tajikistan's northernmost province, Sughd. The development of the risk model involved both extensive fieldwork and computational work, including: soil amplification studies; defining ground shaking scenarios for earthquakes on local active faults that could cause damage, and for historical earthquakes that have caused damage to the city's building stock; demarcation of the Khujand city area and its subdivision into geographical units; definition of building typology classes and generating corresponding vulnerability functions; collection of building inventory data as well as socioeconomic information, and the computation of damage and loss scenarios. The earthquake risk model for the city of Khujand can be used as guidance for local authorities for future city planning and earthquake mitigation actions by helping to predict earthquake intensity in a given location, and the expected damage and socio-economic losses for any class of building. The procedure and many of the conclusions drawn can be applied in risk studies of other areas in Tajikistan and Central Asia.
\end{abstract}

\title{
Keywords:
}

seismic hazard, earthquake loss estimation, analytical vulnerability assessment, economic loss, casualty estimation

\section{Indroduction}

The city of Khujand is the capital of Tajikistan's northernmost province, Sughd, and is the administrative, industrial and cultural centre of northern Tajikistan (see Figure 1a). With an approximate population of 165,000 , it is Tajikistan's second-largest city. The city is situated on the Syr Darya River at the mouth of the Fergana Valley, one of the most seismically active regions of Central Asia. 


\section{Study area: development and seismic hazard situation}

The city of Khujand is the capital of Tajikistan's northernmost province, Sughd, and is the administrative, industrial and cultural centre of northern Tajikistan (see Figure 1a). With an approximate population of 165,000 , it is Tajikistan's second-largest city. The city is situated on the Syr Darya River at the mouth of the Fergana Valley, one of the most seismically active regions of Central Asia.

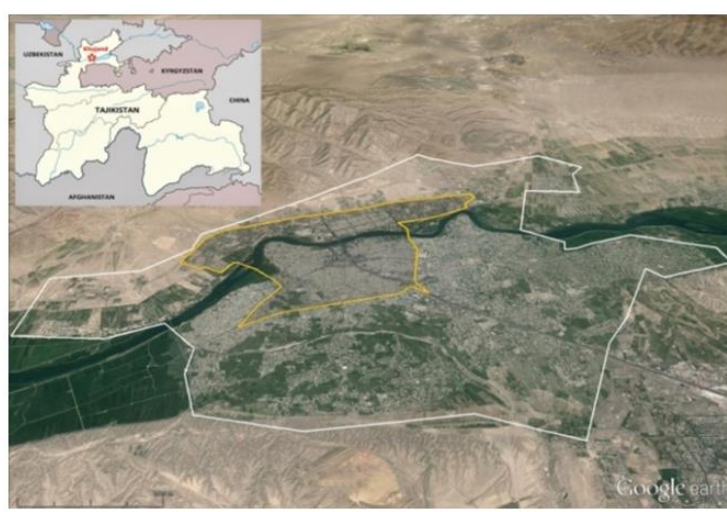

Figure 1a: Location of Khujand in northern Tajikistan and aerial view of the region (GoogleTM Earth). The Khujand city limit is indicated by the orange line, while the white line demarcates Khujand district (Khujand viloyat).

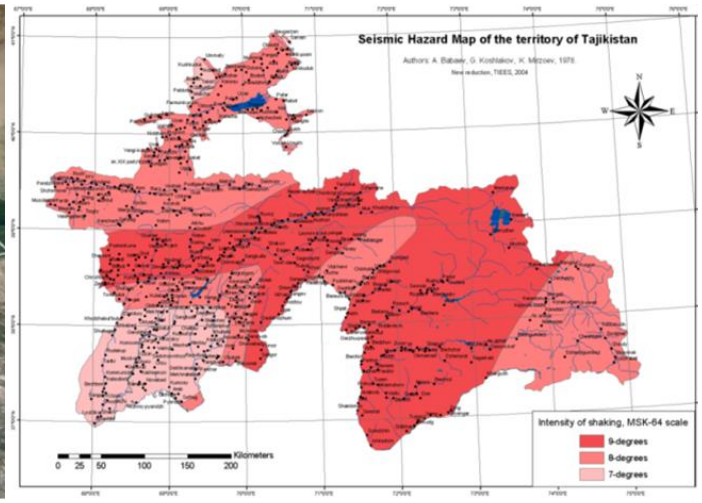

Figure 1b: Seismic hazard map of Tajikistan (Babaev et al., 1978)

According to the seismic hazard map (Babaev et al., 1978) taken from the national seismic building code (SNIP, 2008) for Tajikistan, the city of Khujand is situated in the country's second most active seismic zone, where earthquake intensities up to IMSK = VIII (8.0) are to be expected (see Figure 1b). Based on the mapping of Earthquake Source Zones (ESZ) generated by Babaev et al. (1984), our study considers three potential ESZs capable of generating earthquakes strong enough to cause structural damage to the building stock of Khujand: (1) the North-Fergana fault, Mmax $\leq 7.5$; (2) the Central-Fergana fault, Mmax $\leq$ 6.5; and (3) the South-Fergana fault, $\mathrm{Mmax} \leq 6.5$. 


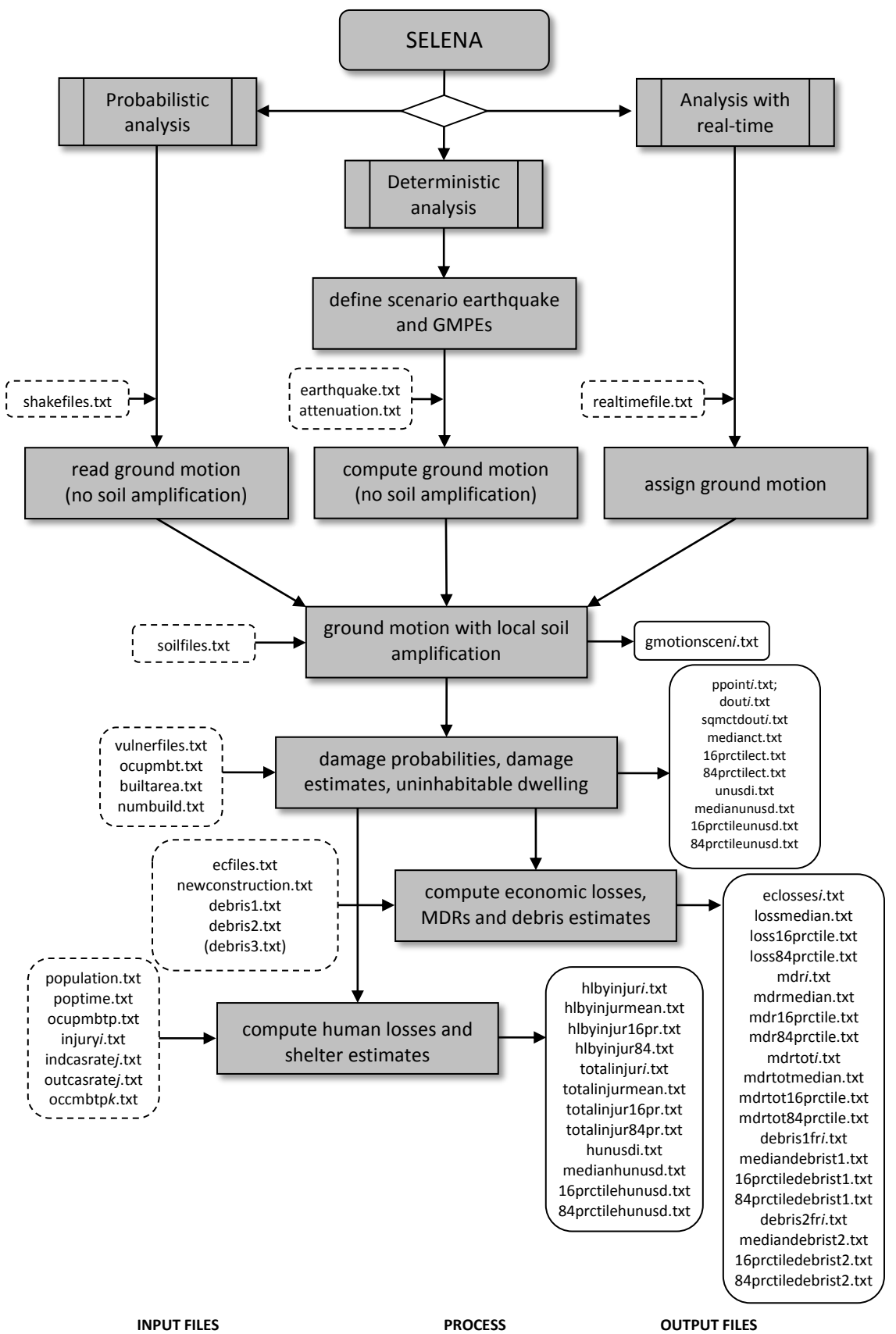

Figure 2: The computation process of the applied software tool SELENA (Source: Molina et al., 2010; Molina et al., 2015). 
The fault lines of these ESZs as well as their potential magnitude ranges were used to decide the locations and strength of a number of scenario events at varying distances from Khujand. In addition, a hypothetical repetition of the two most prominent historical events of the region, i.e. the 1985 Kairakkum (Mw 6.0) and the 1977 Isfara-Batkent (Mw 6.3) earthquakes, were investigated.

\section{Earthquake loss estimates: methodology and tool}

The earthquake risk study of Khujand was carried out using SELENA, an open-source tool developed jointly by NORSAR (Norway) and the University of Alicante (Spain). The software can provide local, state and regional institutions with a state-of-the-art decisionsupport tool for estimating possible losses from future earthquakes (Molina et al., 2015). The methodology for the present study was based on a "scenario earthquake" and a suite of empirical ground-motion prediction models (GMPE) to evaluate the seismic ground-motion distribution and corresponding losses for a city or a region. The user needs to provide earthquake sources, ground-motion prediction equations (GMPE), soil information along with soil amplification factors, built-up areas or number of buildings of different building typologies, capacity curves and fragility curves corresponding to each of the model building types, and finally cost estimates (i.e., building repair and replacement values). Using this information, SELENA computes the probabilities for each of the four levels of damage (i.e., slight, moderate, extensive and complete), and provides the mean damage ratio for each geounit and building typology. Economic losses and human casualties are also estimated. Figure 2 illustrates the flowchart of SELENA, including the necessary input and output files.

\section{Hazard, exposure and vulnerability models for Khujand}

\section{Ground motion input}

\section{Scenario earthquakes}

\section{Historical events:}

A hypothetical repetition of the two most prominent historical earthquake events will also be investigated for the current study, using their original source parameters (see Table 1). The first event is the 1977 Isfara-Batkent earthquake in the south-western part of Ferghana valley, which caused tremors in an extensive border zone between Kyrgyzstan, Tajikistan and Uzbekistan. The intensity of the tremors in the epicentral area reached $\mathrm{I}=7-8$ and magnitude of 6.3 . The focal depth is estimated to have been at $25 \pm 5 \mathrm{~km}$. 
Niyazov et al

Table 1: Source parameters of the historical events and epicentral distances from Khujand.

\begin{tabular}{|l|l|l|l|l|l|l|l|}
\hline \hline Date & Name & Lat. & Long. & Depth $b$ & Magnitude & $\begin{array}{l}\text { Max. } \\
\text { intensity } \\
I_{\text {max }}\end{array}$ & $\begin{array}{l}\text { Epic. distance } \\
\text { to Khujand R }\end{array}$ \\
\hline \hline $\begin{array}{l}\text { 1977, Jan. 31 } \\
(14: 26)\end{array}$ & $\begin{array}{l}\text { Isfara- } \\
\text { Batkent }\end{array}$ & $40.094^{\circ}$ & $70.694^{\circ}$ & $\begin{array}{l}25 \mathrm{~km} \pm 5 \\
\mathrm{~km})\end{array}$ & $M_{w} 6.30$ & $7-8$ & $93 \mathrm{~km}$ \\
\hline $\begin{array}{l}1985, \text { Oct. 13 } \\
(15: 59)\end{array}$ & Kairakkum & $40.262^{\circ}$ & $69.703^{\circ}$ & $10-15 \mathrm{~km}$ & $M_{w} 6.0$ & 8 & $14 \mathrm{~km}$ \\
\hline \hline
\end{tabular}

The second event is the 1985 Kairakkum earthquake, a destructive earthquake that occurred in the Leninabad region of Tajikistan affecting an extensive area of Central Asia and Kazakhstan. The earthquake intensity reached 8 in the epicentral zone. The magnitude of the earthquake is estimated to have been 6.0 , and the focal depth $h=10-15 \mathrm{~km}$.

Deterministic scenario events

In order to investigate potential earthquakes which may be generated by the various ESZs that are close to the city of Khujand, hypothetical scenario earthquakes were defined. The epicentral coordinates of these earthquakes were placed along the known fault lines at various distances from Khujand's centre point (see Figure 3). The focal depths were kept constant at $\mathrm{h}=20 \mathrm{~km}$, while the magnitudes were equal to the maximum magnitudes assigned to the various ESZs.

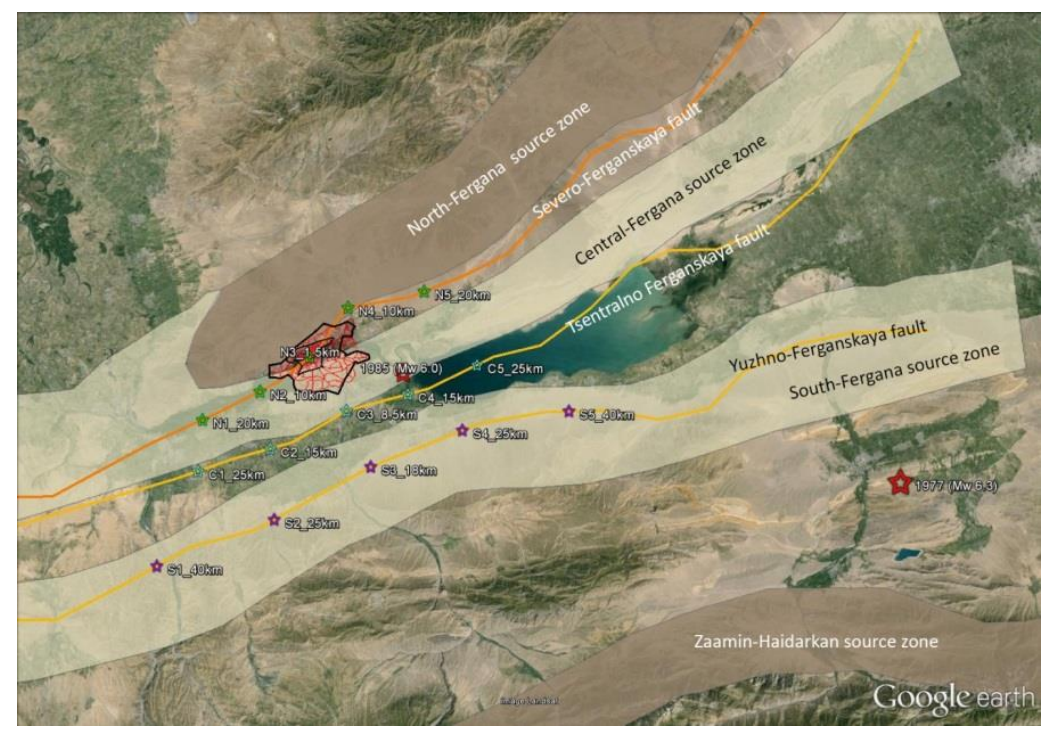

Figure 3: Location of hypothetical earthquake epicentres along the three major fault lines close to Khujand and their respective source zones. 


\section{Ground motion attenuation}

For loss computations based on deterministic scenario events, ground motion prediction equations (GMPEs; also known as "attenuation relations") are required in order to compute (predict) spectral ground motion estimates as a function of source distance. For the current study, where ground motion accelerations are to be provided for Northern Tajikistan, it is necessary to select GMPEs that are representative for the present seismotectonic situation (seismogenic faults and zones) and the seismic hazard level (distance from active faults, magnitude, and depth range of expected earthquakes). All major faults surrounding the city of Khujand are thrust-type faults, with an average focal depth of $20 \mathrm{~km}(\mathrm{~h}=20 \mathrm{~km})$. The magnitude range may be estimated as being between Mw 5.5 and 6.5. GMPE equations that were customized for the territory of Tajikistan or that use regional earthquake data were not available. Hence an alternative GMPE, developed by Ambraseys et al. (2005), was selected as being applicable for the present scenarios. The Ambraseys et al. model was constructed from a combination of data from all seismically active parts of Europe and the Middle East that had a magnitude range $\mathrm{Mw} 5.0-7.6$ (with a scarcity of data for $\mathrm{Mw}>6.5$ ) and a distance range $\mathrm{rjB}<100 \mathrm{~km}$.

\section{Soil model}

The city of Khujand is located in the western part of the Fergana inter-mountain basin. It is framed by the Turkestan and Alai mountain ranges in the south, the Fergana mountain range to the east, and the Kurama Chatkal mountain range in the north. The average altitude of each of these mountain ranges is in excess of 2,000 or 3,000 m. These mountain ranges are cut through by a deep-trough intermountain basin which is approximately $350-400 \mathrm{~km}$ long and up to $150 \mathrm{~km}$ wide.

The geological structure of the area involves intrusive rocks, i.e., soils, granodiorites and diorite Paleozoic rocks (the Mogol-Tau Mountains are to the North). The near-surface geology of the Khujand area is characterized by three soil categories: (1) loess soil terraces at the left bank of the river Syr Darya; (2) gravel-pebble deposits formed by the alluvial terraces of the Syr Darya and the alluvial fan of the river Khoja Bakirgan; (3) block-detrital sediments forming the right bank of the Syr Darya.

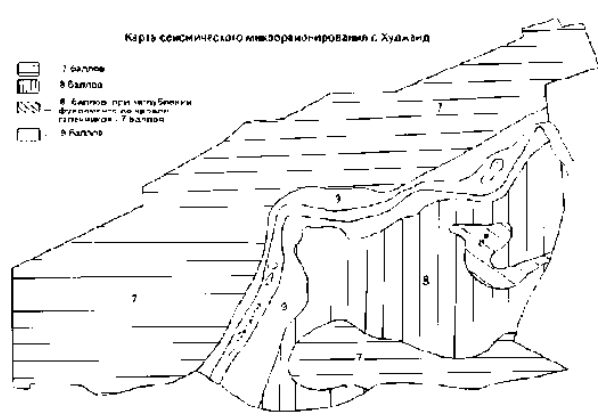

a)

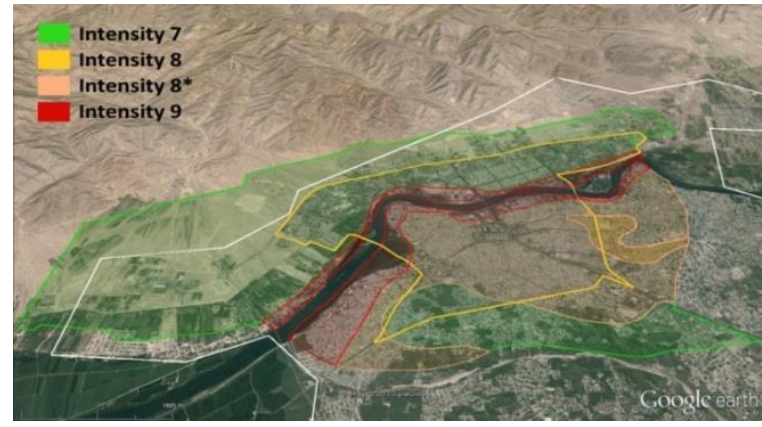

b)

Figure 4: Microzonation map of Khujand city showing seismic intensities: a) original map; b) digitized map on Google Earth. 
The geological surveys carried out in Tajikistan, their analysis, and syntheses of the literature allowed Kogan et al. (1974) to assign macroseismic intensities (following Medvedev's intensity scale) to the geological conditions of Khujand (see Figure 4a). By superimposing the map of seismic intensity classes on the test bed Khujand, it is possible to assign soil classes according to the NEHRP (BSSC 1995) classification scheme as well as Eurocode 8 (EN 1998-1 2004) to each of the 138 geographical units (Figure 5a).

\section{Inventory model}

In general, the generation of an inventory database represents the most time-consuming and often most cumbersome task. Inventory, here, refers not only to the physical assets (buildings and infrastructure, contents etc.) of the study area but also to its inhabitants. An inventory database, at best, should include geo-referenced information on each building's location, structural information that allows a clear designation of its typology class, as well as socio-economic information (value, replacement and repair costs of buildings, population numbers, occupancy pattern, occupancy rates etc.). Socio-economic information is required primarily to compute estimates of economic losses and casualty numbers caused directly by structural damage (Lang, 2013). According to Lang (2013), it is important to determine whether an inventory database (of any type or quality) is already available, or whether one has to be developed from scratch. While the latter case may be more time-consuming, the generation of a customized inventory database may provide better data quality and hence reliability.

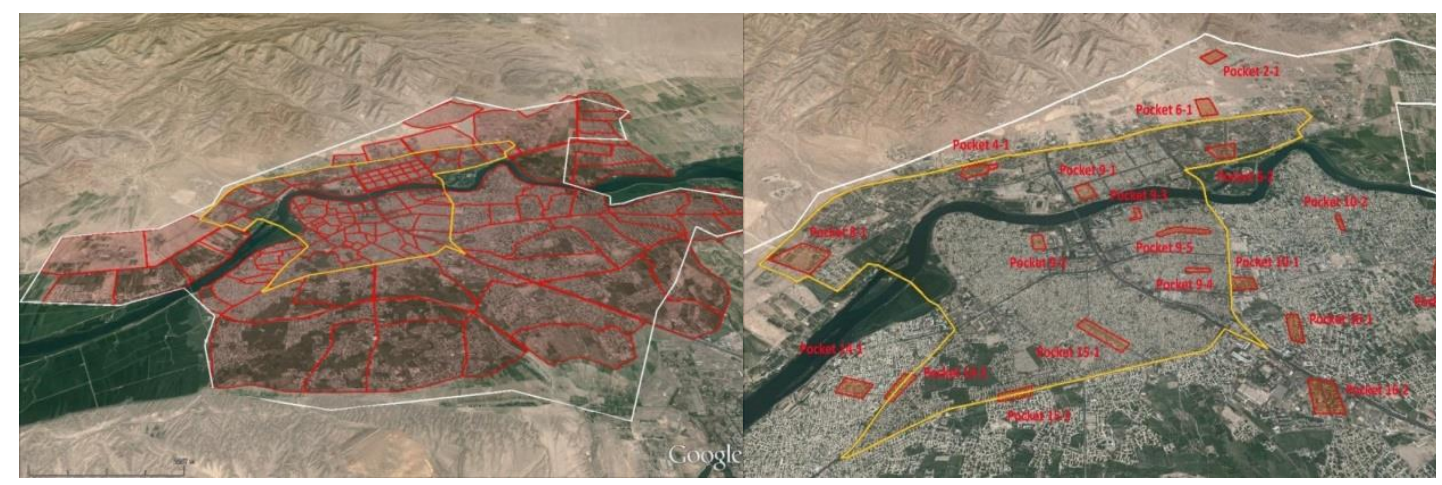

Figure 5a: Subdivision of the territory of Khujand district into 138 geographical units.

Figure 5b: Investigated areas in which the in-situ visual survey concentrated.

The inventory model for the test bed Khujand, which was developed during the present project, is based on random sample surveys and extrapolation from the results of these. The model therefore inherently has a degree of uncertainty and shortcomings compared to a building-by-building database. The individual steps in generating the building stock inventory are:

- Demarcation of the study area, i.e. Khujand district, including urban and suburban areas surrounding Khujand city itself (see Figure 5a). 
- Clustering of the study area into geographical units based on a map that subdivides the city into so-called microrayons. Figure 5a illustrates the 138 geographical units, of which 80 are located within and 58 outside Khujand city itself, thus covering the entire populated territory of Khujand district.

- Conducting in-situ visual surveys in randomly chosen districts of the city (pockets) that represent different socio-economic levels (see Figure 5b). During the survey, various parameters covering the buildings' structural typology, occupancy as well as current condition were identified. Each building is assigned a structural typology class following a homogenous classification scheme for Central Asia (Lang et al., 2016).

- For each pocket, a building typology distribution is identified, which is then extrapolated to those geo-units having similar inventory patterns. The extrapolation is based on estimated/counted numbers of individual buildings in each geo-unit.

\section{Building classification scheme}

The prerequisite for any inventory work is the identification of prevalent building typologies and the conceptual outline of a building classification scheme for the study area. In general, the Central Asian region is characterized by a multitude of vernacular and contemporary construction typologies. However, if only a certain country, region or even city is considered, the number of building typologies may be significantly reduced. This can also be observed for the test bed Khujand, where most of the building typology classes have either been physically identified or been included, since these will probably be found in the close vicinity of Khujand. The building classification scheme originally compiled by Lang et al. (2016) was used, but customized to the peculiarities of building typologies in Khujand.

\section{Structural vulnerability model}

The structural vulnerability to earthquakes of a building typology describes its susceptibility to damage caused by a given ground-shaking level. For the present study, the procedure for calculating building damage and losses (i.e., economic losses and casualties) requires the building vulnerability model to be represented by analytical capacity curves and fragility functions. 


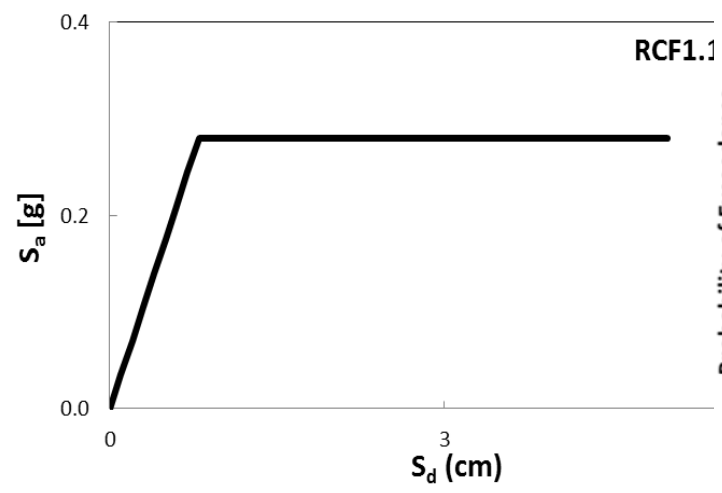

(a) Capacity curve

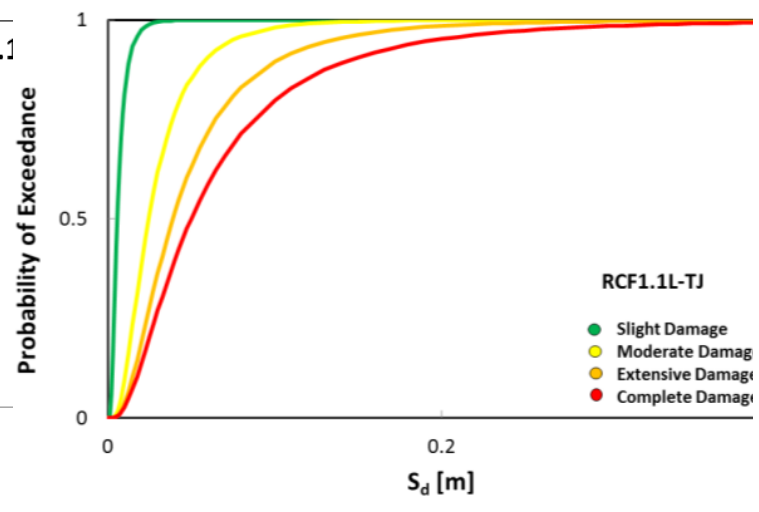

(b) Fragility functions

Figure 6: Example of a vulnerability model generated for non-ductile reinforced-concrete buildings.

The capacity curve is defined as the base shear acting on the building as a function of the building's horizontal roof displacement. In other words, it describes the capacity of a building to resist seismic action (Figure 6a). Fragility functions define the probability of exceeding a given damage state (or performance) as a function of an engineering demand parameter that represents the ground motion (Figure 6b). Using the framework of NORSAR's collaboration project on earthquake hazard and risk assessment in Central Asia (2009-2014), vulnerability models were generated for the existing building typologies in Khujand. Nonlinear static-based analyses were conducted, taking into account the dispersion due to the uncertainty in structural characteristics-related parameters, building-to-building variability, as well as the record-to-record dispersion in ground motion. Figure 6 illustrates an example of a customized vulnerability model for a selected building typology.

\section{Economic values of building inventory}

In order to compute the direct economic losses related to the structural damage of the building stock, repair and replacement values for the various building typologies are required. As a building's function or utilization (occupancy class) strongly affects its economic value (mainly caused by the non-structural components and contents, for example in the case of hospitals), repair and replacement values may differ for buildings of the same typology but different occupancy.

In general, repair values for the lower damage states (Slight, Moderate, Extensive) are a fraction of the replacement value (damage state Complete). The repair and replacement values of a particular building typology may be given as the cost per $1 \mathrm{~m} 2$ in a user-defined currency (e.g. Euros, US Dollars, or Tajik Somoni). The value may incorporate nonstructural components and contents as well as the costs required to, e.g., demolish a severely damaged building and to remove the debris. It should also be noted that the relative replacement (construction) costs (i.e., costs per square metre) may vary according to the height of the building (Lang et al., 2012). 
The economic model for the building stock of Khujand is based on actual construction cost estimates provided by the JSK Scientific-Research and Design Institute (SANIIOSP, Dushanbe) for two categories of building. These construction costs:

- are the actual costs for reconstruction and do not represent market values that are closely connected to demand,

- do not consider the higher costs for construction materials and labour often observed in the aftermath of a natural disaster and caused by increased demand,

- do not account for effects of inflation or speculation.

Based on these storey-dependent estimates and the average storey number $\mathrm{N}$ assigned to each of the 25 building typologies, their reconstruction values per square metre can be computed. It should be explicitly mentioned that these values cover the costs for both the structural and the non-structural components of the buildings. They do not include the costs for building contents (e.g. furniture, laboratory equipment, special facilities for hospitals, etc.). Hence, they do not vary with occupancy class.

In a second step, construction costs including contents are estimated based on the values initially provided in the American Applied Technology Council document ATC-13 (Applied Technology Ccouncil, 1985) and later accepted by HAZUS®99 (Federal Emergency Management Agency, 1999), as well as our own estimates that may serve as a better basis for the situation in Tajikistan. For each occupancy class, content values are given as a percentage of the facility's replacement value.

To estimate the final replacement and repair values for the various building typologies and occupancy classes, it is necessary to determine cost ratios (also referred to as damage ratios, DRi) dependent on damage state $i$ as well as costs for partial demolition (especially for damage state extensive) and debris removal (for damage states Extensive and Complete). With respect to demolition costs, the following aspects were considered:

- Demolition costs arise exclusively for buildings suffering Extensive damage. This type of damage is considered non-repairable and a repair would not be costeffective. These buildings need to be demolished before reconstruction is started.

- Demolition costs do not occur for buildings suffering Complete damage as these buildings are already partially collapsed and hence only minor demolition is required.

- Demolition costs increase with the amount of reinforced-concrete elements (e.g. RC confinements, slabs, lintel bands, columns and beams, shear walls) or internal reinforcement (e.g. reinforced clay brick or concrete-block masonry walls).

The cost estimates for debris removal are based on the following considerations:

- Costs for debris removal apply only to buildings suffering Extensive and Complete damage.

- Costs for debris removal increase with the heterogeneity of building materials and the labour for handling these materials.

- In the case of adobe buildings, costs for debris removal are assumed to be low as the material to be disposed of is mainly earthen. 
- In the case of clay brick masonry buildings, costs for debris removal are assumed to be low as bricks will mostly be reused by the owner or builders.

- In the case of timber buildings, no costs for debris removal are assumed as timber elements will be either reused or burned.

The damage (cost) ratios DRi for damage states Slight, Moderate, and in some cases Extensive have been taken in part from various references (e.g., Bal et al., 2008; Federal Emergency Management Agency, 2003; Lang et al., 2012) and are considered realistic estimates for the present study.

\section{Population}

According to the census conducted in 2010, the population of the city of Khujand was estimated at 165,000. Since no more reliable numbers are available, this estimate is used as the basis for the calculation of the population distribution over the 81 geo-units located within the city boundary. The distribution of the population over these geo-units is done in a linear fashion, dependent on the total floor area of the buildings in each geo-unit. The calculation of the population based on this same total geo-unit floor area is considered to be more accurate than using the number of individual buildings.

The population numbers in the remaining 57 geo-units which cover Khujand district are calculated using the ratio of the total floor area in buildings to the number of individual buildings:

- For geo-units with an average building floor area $>2,500 \mathrm{~m} 2$, the estimate of the population takes the occupancy density observed for the city of Khujand, i.e. 35.8 $\mathrm{m} 2 /$ person.

- For geo-units with an average building floor area $<2,500 \mathrm{~m} 2$, the estimate of the population takes an occupancy density of 9 persons/building.

Using these estimates, a total population of 149,673 for the 57 geo-units of Khujand district is derived. The entire study area, i.e., Khujand city and Khujand district, consequently adds up to 314,673 inhabitants.

\section{Damage and loss computations: results and discussion}

\section{Results and discussion from the historical scenarios}

In the discussion below, earthquake loss estimates are provided for the two main historical earthquake events, i.e. the 1977 Isfara-Batkent ( Mw 6.3) earthquake, and the 1985 Kairakkum (Mw 6.0) earthquake. Figure 7a shows an example of the spatial distribution of ground motion shaking (in terms of PGA), 7b shows damage probabilities, $7 \mathrm{c}$ the mean damage, and $7 \mathrm{~d}$ economic losses for the 1985 Kairakkum earthquake. 


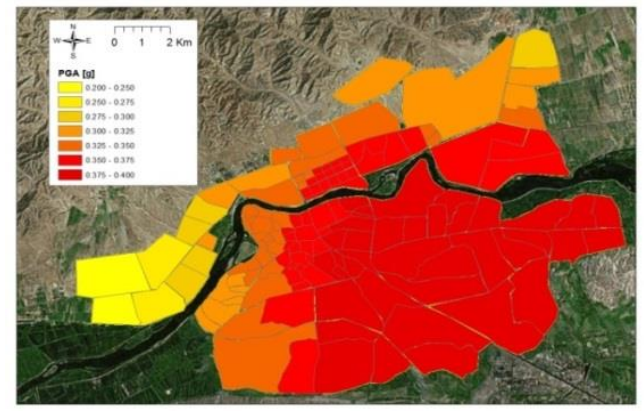

(a) Ground motion shake maps (PGA for soil)

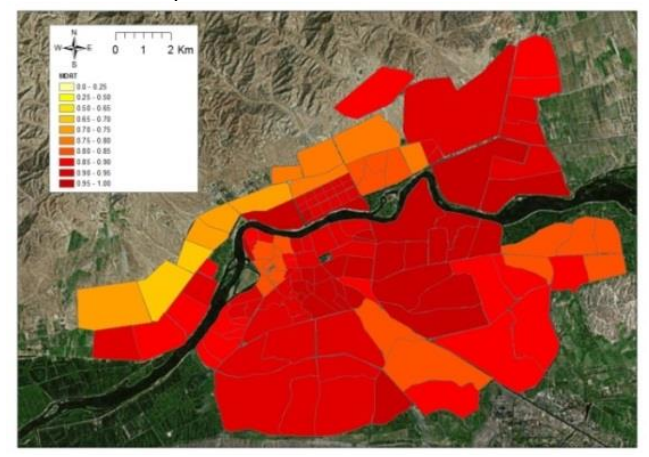

(c) Mean damage ratio

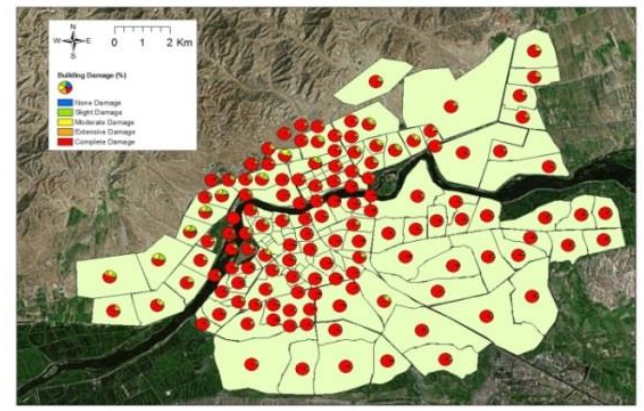

(b) Damage probabilities

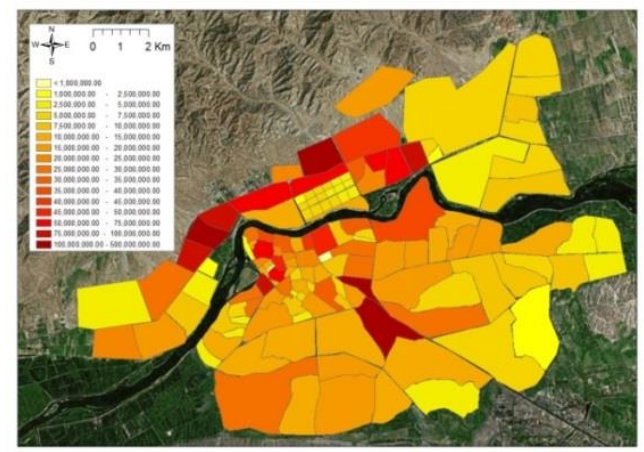

(d) Economic losses

Figure 7: Results of earthquake damage and losses for the 1985 Kairakkum earthquake (MW 6.0 at D $=14 \mathrm{~km})$.

Due to the combination of a significant magnitude and a very small epicentral distance, the predicted ground motion level is extremely high; significant attenuation effects can therefore also be observed over the study area (Figure 7a). The ground motion estimates include soil amplification effects, which can be clearly seen by the red-shaded geo-units on both sides of the river banks and south-east of the river. The highest PGA is concentrated mainly in the southeastern area of the test bed, measuring 0.375 to $0.4 \mathrm{~g}$. The western part shows the lowest PGA among all geo-units, between 0.2 and $0.25 \mathrm{~g}$. The predicted ground motion intensity level would be likely to generate complete structural devastation of most building typologies. The estimated damage probabilities, mean damage ratio and economic losses over all building typology classes reflect the distribution of ground motion. 


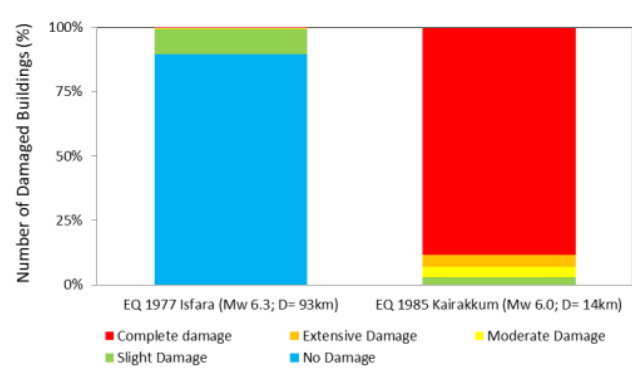

(a) Cumulative damage distribution

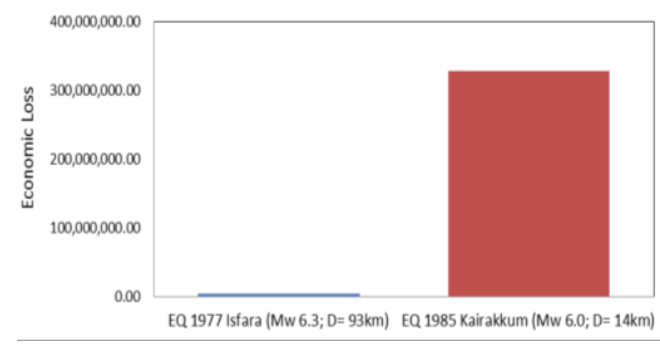

(b) Cumulative economic losses distribution

Figure 8: Earthquake loss estimates over all building typologies and geo-units for the two historical earthquakes (1977, Isfara-Batkent, Mw 6.3; 1985, Kairakkum, Mw 6.0).

Figure 8 illustrates the cumulative damage and economic loss distributions for both the 1977 and the 1985 events. The effect of epicentral distance can be seen clearly in Figure 8. In contrast to the 1985 Kairakkum earthquake, which was located $14 \mathrm{~km}$ from Khujand city centre, the 1977 Isfara-Batkent earthquake was too far $(93 \mathrm{~km})$ to produce significant damage to most of the building typologies present in the city at that time. It should be noted that the hypothetical repetition of an historical event in an earthquake loss estimation (ELE) study, especially after a certain period of time has passed, is often fruitless, notably because the test bed's building stock in terms of both size and composition may have changed significantly in the meantime. Hence the damage predicted by the present study is significantly different from the actual damage that occurred during the historical event (Lang et al., 2012).

\section{Results and discussion from deterministic scenario events}

Cumulative damage and economic loss results for a suite of theoretically assumed scenario earthquakes placed along the main fault lines close to the city (see Figure 3) are provided in Figure 9. As illustrated for the Severo-Ferganskaya event, the effect of distance from Khujand's centre is almost negligible compared to that of magnitude. In fact, an assumed maximum magnitude of $\mathrm{Mw} 7.5$ would lead to the complete damage of almost $80 \%$ of the building stock, so the complete damage of almost all adobe and unreinforced brick masonry buildings, and of non-ductile/low-code RC buildings.

However, in the case of the Tsentralno-Ferganskaya and Yuzhno-Ferganskaya events, where a maximum magnitude of M 6.5 was assumed, the effect of epicentral distance can be clearly seen. It is estimated that for the Tsentralno-Ferganskaya event, 45 to $75 \%$ of the building stock could suffer complete or at least severe damage. Where the Yuzhno-Ferganskaya fault is concerned, and depending on the epicentral distance, estimates for the percentage of the building stock that could suffer complete or severe damage vary between $25 \%$ and up to $60 \%$, thereby affecting mainly the most vulnerable buildings. 


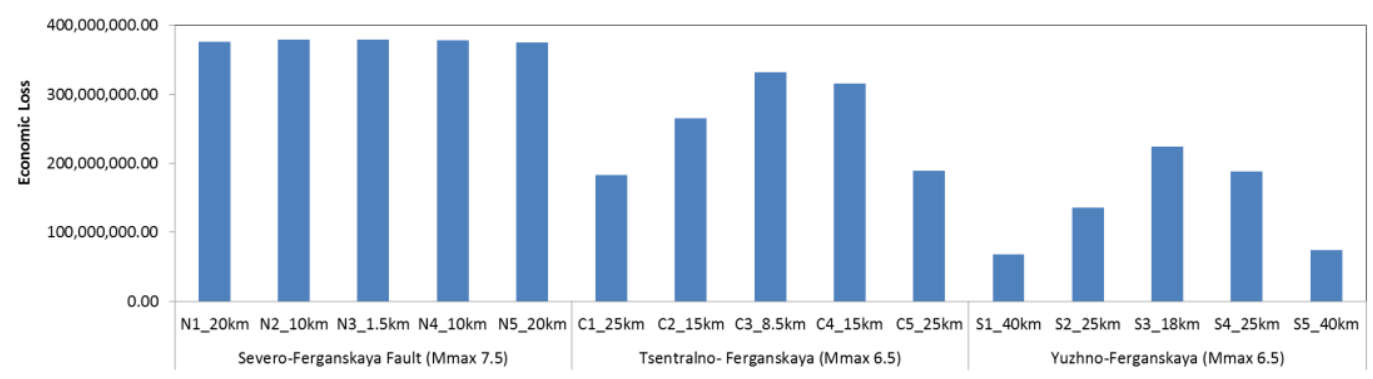

(a) Cumulative damage distribution

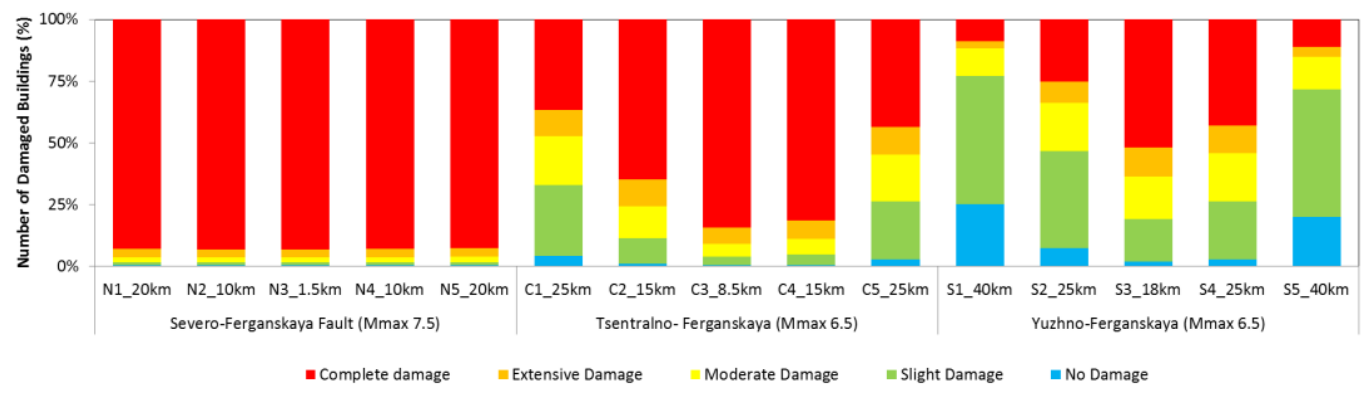

(b) Distribution of cumulative economic losses

Figure 9: Cumulative damage distribution over all building typologies and geo-units for the deterministic scenario events placed along the main fault lines at various distances from Khujand.

\section{Conclusions}

This article presents results of an earthquake loss estimation (ELE) study conducted within the framework of NORSAR's collaborative project on earthquake hazard and risk assessment in Central Asia funded by the Royal Norwegian Ministry of Foreign Affairs. The aim of this project was to provide local authorities with an earthquake risk model that can be used as guidance for future city planning and earthquake mitigation actions. It can provide a useful tool in predicting the expected earthquake intensity at a given location, and the expected damage and socio-economic losses for any class of building. In total, two historical earthquake events and 15 deterministic earthquake scenarios were considered for the ELE. The outcomes of the risk assessment have shown that most of the existing building typology classes in the region would suffer severe damage. However, it is important to note that the various results for damage ratio and losses presented in this study are associated with a number of epistemic uncertainties that need to be taken into account at the mitigationplanning phase. 


\section{References}

Akkar, S., \& Bommer, J.J. (2007). Prediction of elastic displacement response spectra in Europe and the Middle East. Earthquake Engineering and Structural Dynamics, 36(10), 1275-1301.

Ambraseys, N.N., Douglas, J., Sarma, S.K., \& Smit, P.M. (2005). Equations for the estimation of strong ground motions from shallow crustal earthquakes using data from Europe and the Middle East: Horizontal peak ground acceleration and spectral acceleration. Bulletin of Earthquake Engineering, 3, 1-53.

Applied Technology Council (1985). Earthquake damage evaluation data for California. Report No. ATC-13, Redwood City, CA.

Babaev, M.A., Koshlakov, G.V., \& Mirzoev, K.M. (1978). Seismic zonation of Tajikistan. Dushanbe. Donish, 68c. [original reference in Russian language].

Babaev, A.M, Ischuk, A.R., \& Negmatullaev, S.H. (2008). Seismic conditions in the territory of Tajikistan. Edition IEE\&S AS RT, Dushanbe. 94c. [original reference in Russian language].

Babaev, A.M., Lyskov, L.M., Mirzoev, K.M., Achilov, G.S., Lazaridi, L.K., \& Radjabov, N.R. (1984). The natural resources of the territory of Tajikistan. Seismogenic zones. Scale 1:500000. GUGK USSR. [original reference in Russian language]

Bal, I.E., Crowley, H., Pinho, R., \& Gülay, G. (2008). Detailed assessment of structural characteristics of Turkish RC building stock for loss assessment models. Soil Dynamics and Earthquake Engineering, 28, 914-932.

Building Seismic Safety Council (1995). NEHRP Recommended Provisions for Seismic Regulations for New Buildings, FEMA 222A/223A, Vol. 1 (Provisions) and Vol. 2 (Commentary). Federal Emergency Management Agency, Washington, DC.

Burt, J.E., \& Barber, G.M. (1996). Elementary Statistics for Geographers. New York, NY: Guilford Press,

Douglas, J. (2011). Ground-motion prediction equations 1964-2010. PEER Report 2011/102, Pacific Earthquake Engineering Research Center, College of Engineering, University of California, Berkeley. [Also published as Final Report BRGM/RP-59356-FR by BRGM]

EN 1998-1 (2004). Eurocode 8 - Design for Structures for Earthquake Resistance, Part 1: General Rules, Seismic Actions and Rules for Buildings. European Committee for Standardization (CEN), Brussels, Belgium, December 2004.

Erduran, E., \& Lang, D.H. (2012). Sensitivity of earthquake risk models to uncertainties in hazard, exposure and vulnerability parameters. NED University Journal of Research, 9, 2, 73-86.

Federal Emergency Management Agency (1999). HAZUS®99 Earthquake Loss Estimation Methodology. User Manual. Federal Emergency Management Agency, Washington, DC.

Federal Emergency Management Agency (2003). HAZUS-MH MR4 Technical Manual. Washington, DC.

ICC (2006) International Building Code 2006, International Code Council, Country Club Hills, IL.

Ischuk, A.R., \& Ilyasova Z.G. (2011). A new map of seismic zonation of the territory of Tajikistan. In Fifth International Symposium on Modern Problems of Geodynamics and Geo-Ecology, Bishkek (Kyrgyzstan), 19-24 June 2011 (pp. 32-39). [original reference in Russian language]

Kogan, A.L., Nechaev, V.A., \& Romanov, A.O. (1974). Seismic microzonation in Tajikistan. Donish, Dushanbe, 1974. [original reference in Russian language].

Lang, D.H. (2013). Earthquake damage and loss assessment - predicting the unpredictable. PhD dissertation, University of Bergen, Norway.

Lang, D.H., Kumar, A., Sulaymanov, S., \& Meslem, A. (2016 draft). Building typology classification and earthquake vulnerability scale of central and south asian building stock.

Lang, D.H., Molina-Palacios, S., Lindholm, C.D., \& Balan, S. (2012). Deterministic earthquake damage and loss assessment for the city of Bucharest, Romania. Journal of Seismology, 16(1), 67-88. 
Molina, S., Lang, D.H., \& Lindholm, C.D. (2010). SELENA - An open-source tool for seismic risk and loss assessment using a logic tree computation procedure. Computers \& Geosciences, 36, 257-269.

Molina, S., Lang, D.H., Meslem, A., \& Lindholm, C.D. (2015). User Manual for the Earthquake Loss Estimation Tool: SELENA. NORSAR, Kjeller Norway.

http://www.riesgosismico.es/selenamanual.pdf). June 2015.

SNIP (2008). Construction in seismic regions: norms of designing, SNIP 22-07-2007 (MKC ЧT 22-072007). Dushanbe, 2008, 85 p. [original reference in Tajik and Russian languages]

Wald, D.J., Quintoriano, V., Heaton, T.H., \& Kanamori, H. (1999). Relationships between peak ground acceleration, peak ground velocity, and Modified Mercalli intensity in California. Earthquake Spectra, 15, 557-564. 